\title{
CFD ANALYSIS FOR A REMOTELY OPERATED VEHICLE IN HORIZONTAL PLAN
}

\author{
Article DOI : $\underline{\text { https://doi.org/10.35219/mtd.2018.2.01 }}$ \\ Andra Teodora NEDELCU ${ }^{1{ }^{*}}$, Catalin FAITARB, Mihail Lucian DUMITRACHE ${ }^{2)}$ \\ 1) Mircea cel Batran Naval Academy, Faculty of Navigation and Naval Transport, 1 Fulgerului, RO- \\ 900218, Constanta, Romania \\ ${ }^{2)}$ Maritime University of Constanta, Faculty of Naval Electromechanics, 104 Mircea cel Batran, RO- \\ 900663, Constanta, Romania \\ *Corresponding author: andra.nedelcu@anmb.ro
}

\begin{abstract}
Nowadays, the concept of a robotic underwater vehicle capable to move independently, autonomously or remotely, has a great potential and a large application. This kind of underwater vehicles are essential tools for providing safe access to the underwater world.

The underwater vehicles are used in many underwater applications including ocean research for taking samples, inspection and repair different undersea structures.

In a general expression, the vehicle replaces the work of divers and represents an integral part of scientific equipment. This paper provides a CFD analysis for an underwater vehicle in horizontal plan for different velocities to obtain several hydrodynamic force characteristics. The body vehicle is modeled with a Six-Degree-of-Freedom (6-DOF) equation of motion that reflects its hydrodynamics characteristics.
\end{abstract}

Keywords: Underwater vehicles, ROV, AUV, 6-DOF.

\section{INTRODUCTION}

Nowadays, the concept of robotic underwater vehicle, capable to move independently, autonomously or remotely, has a great potential and a large application. This kind of underwater vehicles are essential tools for providing safe access to the underwater world.

Underwater vehicles can be used for ocean response exploration and exploitation, pipeline inspection, offshore structure maintenance, seafloor geography mapping and other uses. In a general expression, the vehicle replaces the work of divers and represents an integral part of scientific equipment. The underwater vehicles are divided into categories: non-autonomous remotely operated vehicles (ROVs) and autonomous underwater vehicles (AUVs). The remotely operated vehicles are controlled and powered from the surface by an operator/pilot, via an umbilical or using remote control, whereas AUVs operate independently of humans (Fig. 1).

The remotely operated vehicles represent the major importance to carry out several tasks in deeper and riskier areas where the use of human divers is impractical. However, there are some challenges in operating the ROVs precisely; such as unpredictable disturbance like current and waves in its operating environment.

In this study, the authors present an experimental analysis of the hydrodynamic behavior of a ROV in horizontal plan. The ROV used for simulation has a closed-frame, similar to a submarine, with 6 degree of freedom.

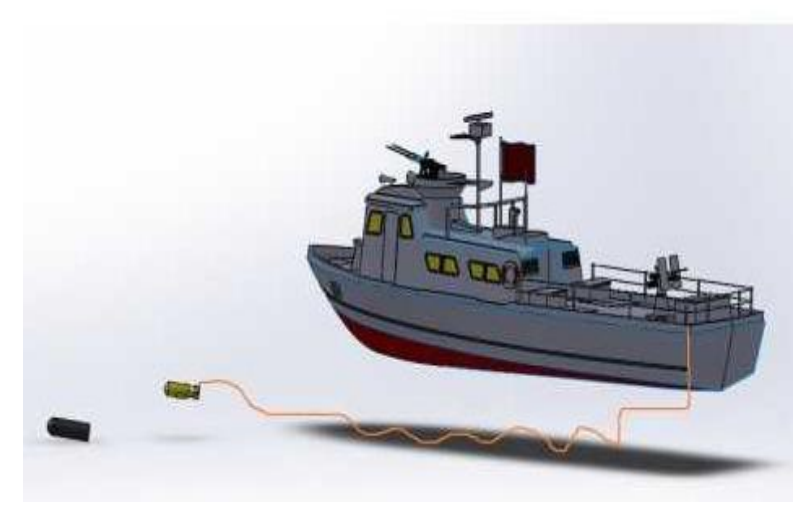

Fig 1. Difference between the ROV and AUV

For an underwater vehicle moving in deep water, at a constant speed, without taking into consideration the surface water effect, the hydrodynamic forces and 
moments are caused by the fluid viscosity, which depends on the geometry and motion velocities. In general, they may be expressed as follows:

$$
\begin{gathered}
\vec{F}_{D}=\vec{F}_{D}(\vec{U}) \\
\vec{F}_{D}=\{X, Y, Z, K, Z, M, N\} \\
\vec{U}=[u, v, w, p, q, r]
\end{gathered}
$$

In this case, the component of forces and moments can be expressed by the multivariate Taylor series of the velocities. For example, if one simplifies the series to the second order, the forces and moments may be expressed as follows:

$$
\begin{aligned}
& X=X_{u} u+X_{u u} u^{2}+X_{w} w+X_{w w} w^{2} \\
& Z=Z_{u} u+Z_{u u} u^{2}+Z_{w} w+Z_{w w} w^{2} \\
& M=M_{u} u+M_{u u} u^{2}+M_{w} w+M_{w w} w^{2}
\end{aligned}
$$

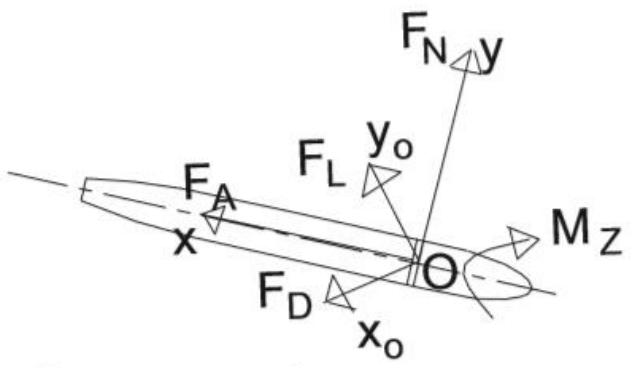

Fig. 2. Body, coordinate systems and component forces

The final forces and moments acting on the model in the body coordinate system are obtained as follows:

Axial force is

$$
\left(F_{A}\right)=A_{x}
$$

Normal force is

$$
\left(F_{N}\right)=N_{1}+N_{2}
$$

The axial and normal force coefficients are obtained as follows:

$$
\begin{aligned}
C_{A}= & \frac{F_{A}}{0.5 \rho \cdot U^{2} \cdot \nabla^{\frac{2}{3}}} \\
C_{N}= & \frac{F_{N}}{0.5 \rho \cdot U^{2} \cdot \nabla^{\frac{2}{3}}}
\end{aligned}
$$

To maintain the uniformity in presenting the force components, both in experimental and numerical investigations, it is necessary to determinate the drag and lift forces. The authors solve and obtain the drag and lift forces on the body by calculating the axial and normal components of the forces, from the body coordinate system presented in Fig. 2.

Drag force is

$$
\left(F_{D}\right)=F_{A} \cos \alpha-F_{N} \sin \alpha
$$

Lift force is

$$
\left(F_{L}\right)=-\left(F_{N} \cos \alpha+F_{A} \sin \alpha\right)
$$

The drag and lift moment coefficients are obtained as follows:

$$
\begin{gathered}
C_{D V}=\frac{F_{D}}{0.5 \rho \cdot U^{2} \cdot \nabla^{\frac{2}{3}}} \\
C_{L V}=\frac{F_{L}}{0.5 \rho \cdot U^{2} \cdot \nabla^{\frac{2}{3}}} \\
C_{M V}=\frac{M_{Z}}{0.5 \rho \cdot U^{2} \cdot \nabla^{\frac{2}{3}} \cdot L}
\end{gathered}
$$

\begin{tabular}{|c|c|c|}
\hline Physical property & Value & Units \\
\hline Length overall & 1200 & {$[\mathrm{~mm}]$} \\
\hline Diameter of body & 300 & {$[\mathrm{~mm}]$} \\
\hline $\begin{array}{l}\text { Diameter } \\
\text { propellers }\end{array}$ & 120 & {$[\mathrm{~mm}]$} \\
\hline Number of propellers & 5 & [piece] \\
\hline Length of wings & 165 & {$[\mathrm{~mm}]$} \\
\hline Number of wings & 4 & [piece] \\
\hline Diameter of tail & 90 & {$[\mathrm{~mm}]$} \\
\hline
\end{tabular}

where the $C_{D V}$ is the drag force coefficient, $C_{L V}$ is the lift force coefficient, $\rho$ is the density of water, $U$ is the towing speed, $\nabla$ is the volume of the body, $L$ is the length of the body and $\alpha$ is the angle of attack, in degrees.

\section{SIMULATION}

The main parameters are summarized in Table 1 . The frame structure is made of steel, while the other components within the frame, such as the thruster and equipment blocks, are made of buoyancy material.

The design is presented in Fig. 3, using ANSYS CFX software.

Table 1. Design particularities of the ROV 


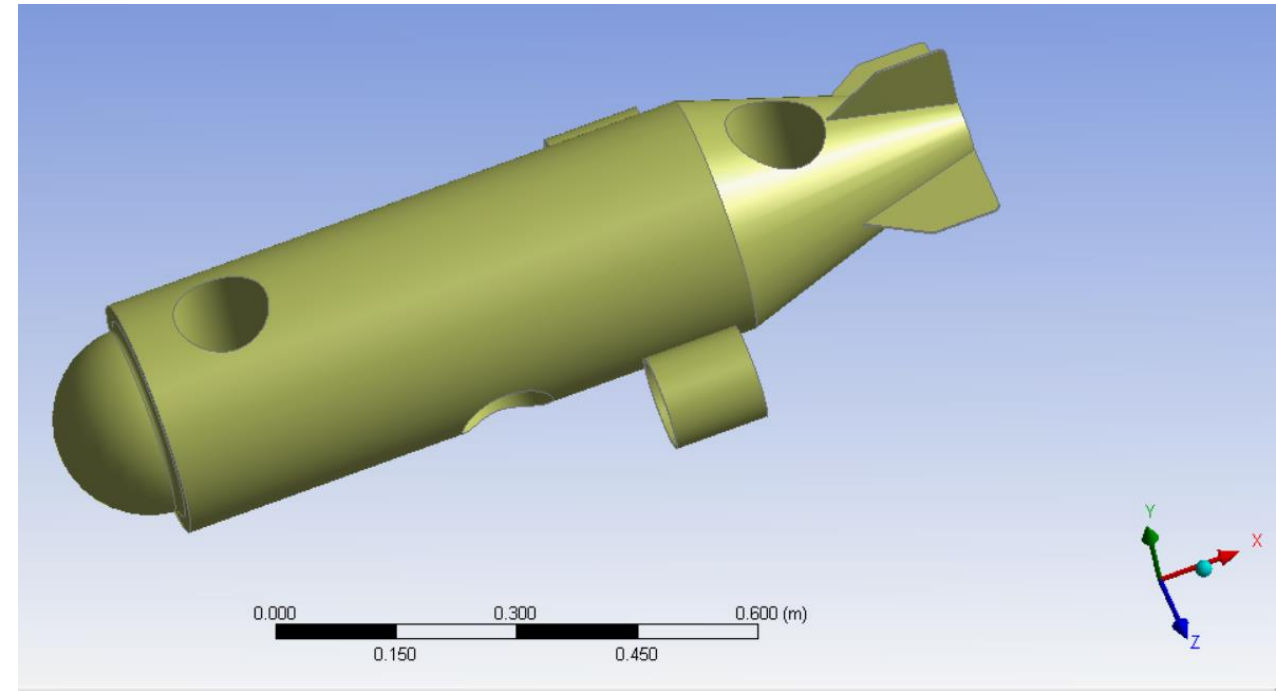

Fig. 3. ROV model

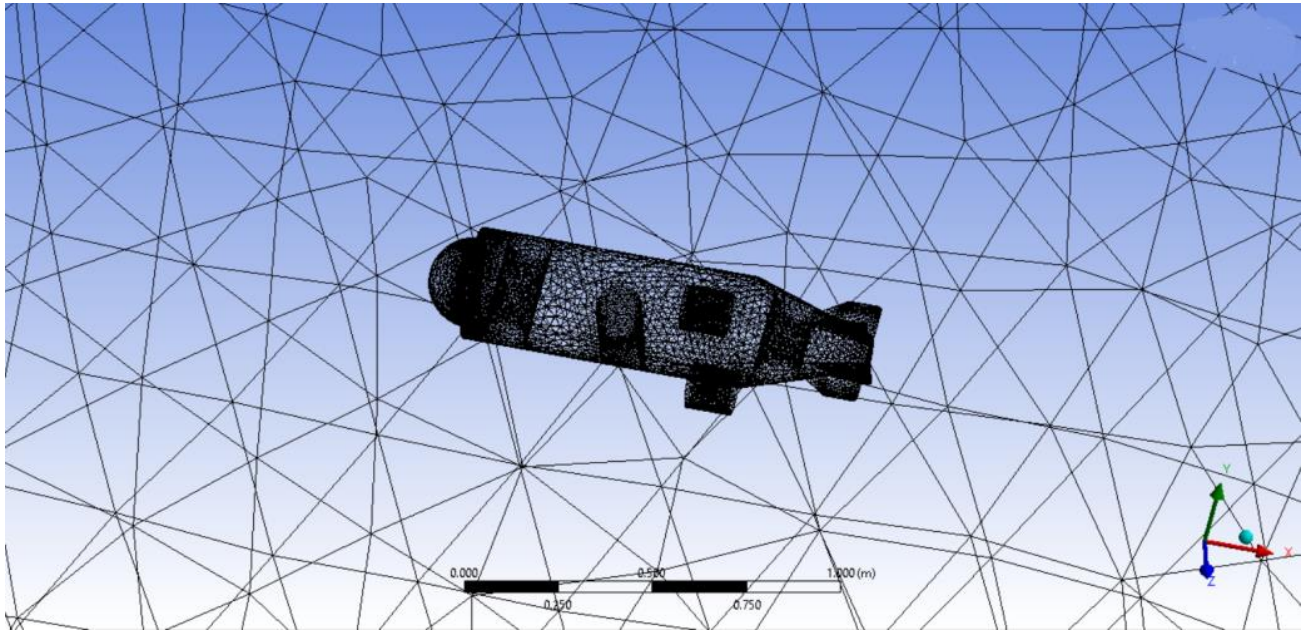

Fig. 4. Volumetric meshing for ROV

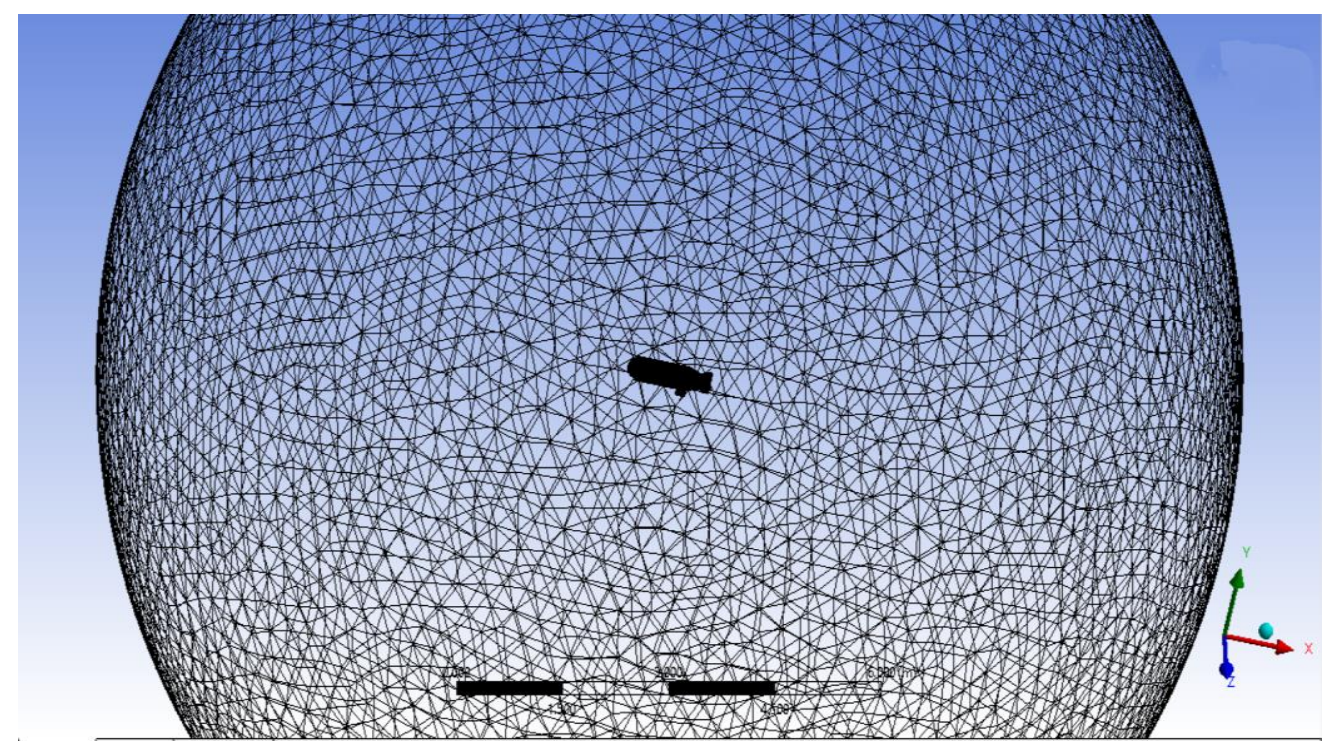

Fig. 5. The sphere domain 
Before performing the CFD simulation, the mesh size needs to be properly defined as the shape of the boundary. Using ANSYS CFX software, in this case, the number of elements are approximately 756330 elements. The fluid domain has around 135403 nodes. The volume is $2232.9 \mathrm{~m}^{3}$. The $3 \mathrm{D}$ view of volumetric mesh of the flow domain around ROV it is represented in Figure 4.

The authors consider the domain (the sphere) full of water (Fig. 5) with the follow conditions, presented in Tabel 2.

Tabel 2. Fluid domain data

\begin{tabular}{lll}
\hline Fluid domain data & Value & Units \\
\hline Density & 997.0 & {$\left[\mathrm{~kg} / \mathrm{m}^{3}\right]$} \\
Molar mass & 18.02 & {$[\mathrm{~kg} / \mathrm{kmol}]$} \\
Specific heat capacity & 4181.7 & {$[\mathrm{~J} / \mathrm{kg} \cdot \mathrm{K}]$} \\
Reference pressure & 1 & {$[\mathrm{~atm}]$} \\
Reference temperature & 25 & {$\left[{ }^{\circ} \mathrm{C}\right]$} \\
Dynamic viscosity & $8.899 \mathrm{E}-4$ & {$[\mathrm{~kg} / \mathrm{m} \cdot \mathrm{s}]$} \\
Thermal conductivity & 0.6069 & {$[\mathrm{~W} / \mathrm{m} \cdot \mathrm{K}]$} \\
Absorption coefficient & 1.0 & {$[1 / \mathrm{m}]$} \\
Thermal expansion coefficient & $2.57 \mathrm{E}-04$ & {$[1 / \mathrm{K}]$} \\
\hline
\end{tabular}

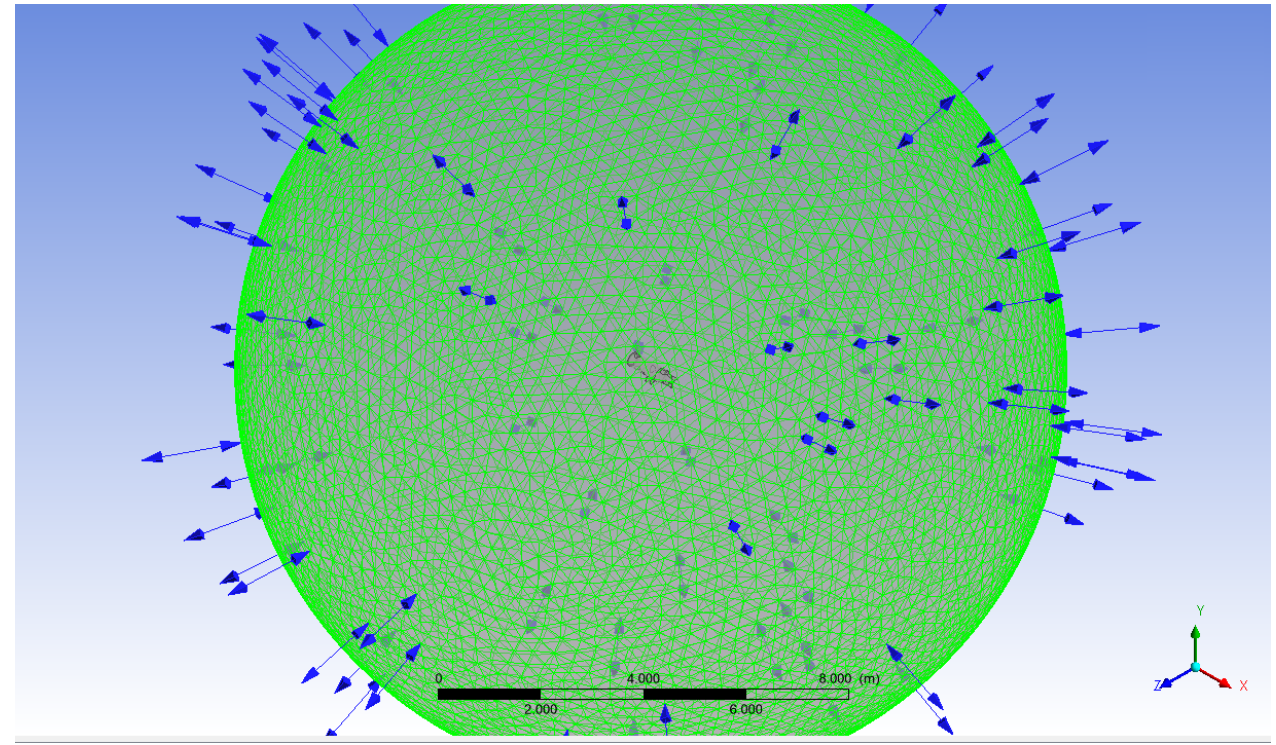

Fig. 6. The boundary conditions

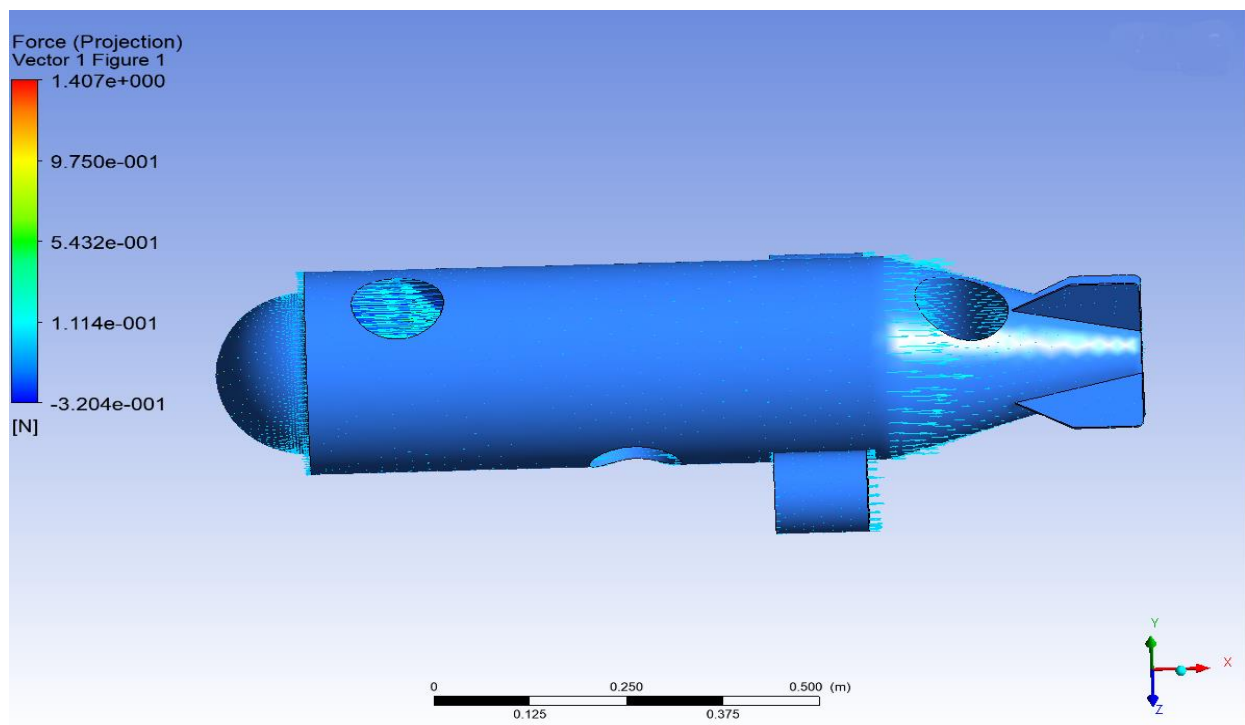

Fig. 7. Vector force 
Table 3. Value for the domain

\begin{tabular}{llll}
\hline Default Domain & X-Comp. & Y-Comp. & Z-Comp. \\
\hline Pressure force on walls & $7.5096 \mathrm{E}+01$ & $6.3069 \mathrm{E}-01$ & $-3.5662 \mathrm{E}+00$ \\
Viscous force on walls & $2.5405 \mathrm{E}+00$ & $6.8692 \mathrm{E}-02$ & $7.2804 \mathrm{E}-02$ \\
Pressure moment on walls & $1.7872 \mathrm{E}-01$ & $2.1962 \mathrm{E}+00$ & $1.4031 \mathrm{E}+00$ \\
Viscous moment on walls & $2.7021 \mathrm{E}-02$ & $-4.1126 \mathrm{E}-02$ & $1.0573 \mathrm{E}-01$ \\
\hline
\end{tabular}

Figure 6 presents the boundary conditions for the domain. The flow regime inside the sphere is subsonic, the vehicle reached a velocity of $2 \mathrm{~m} / \mathrm{s}$.

During the simulation, the vehicle achieves a speed of $2 \mathrm{~m} / \mathrm{s}$. Other initial conditions are water temperature $25^{\circ} \mathrm{C}$ and a turbulent flow.

Figure 7 presents the vector force concerning the vehicle body. After simulation, the authors observed an absolute pressure reaching the minimum value of 98107.5 $\mathrm{Pa}$ and the maximum value of $103277 \mathrm{~Pa}$.

The total pressure value is between $-2726.72 \mathrm{~Pa}$ along the body vehicle and $2347.92 \mathrm{~Pa}$ around the holes for propulsions.
Table 3 presents the values for different variable for the domain (the sphere).

The velocity reached a minimum value of 0.016 $\mathrm{m} / \mathrm{s}$, concerned to the stern of vehicle, and a maximum value of $2.642 \mathrm{~m} / \mathrm{s}$.

The simulated result is going to be verified with the experimental tests, in basic and sea water. Future works could improve the accuracy of the CFD results by comparing the numerical simulation with the ROV, using real-time adaptive identification approach in sea trial.

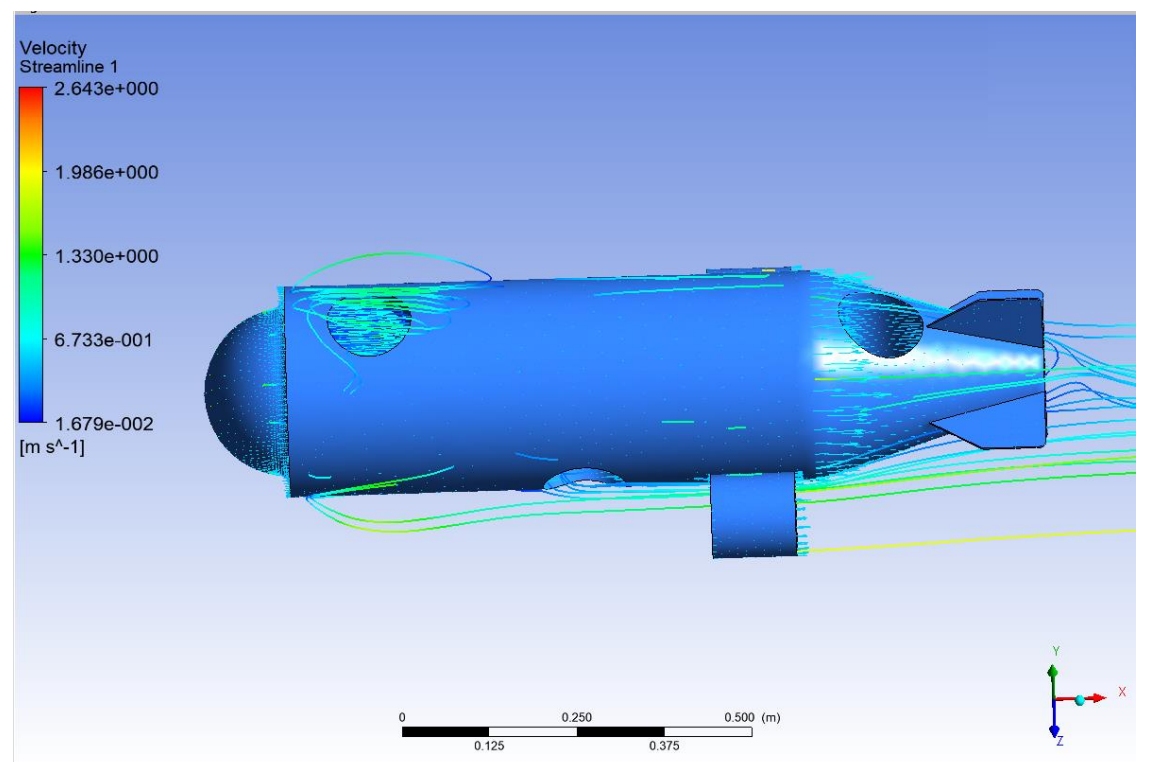

Fig. 8. Velocity over vehicle body

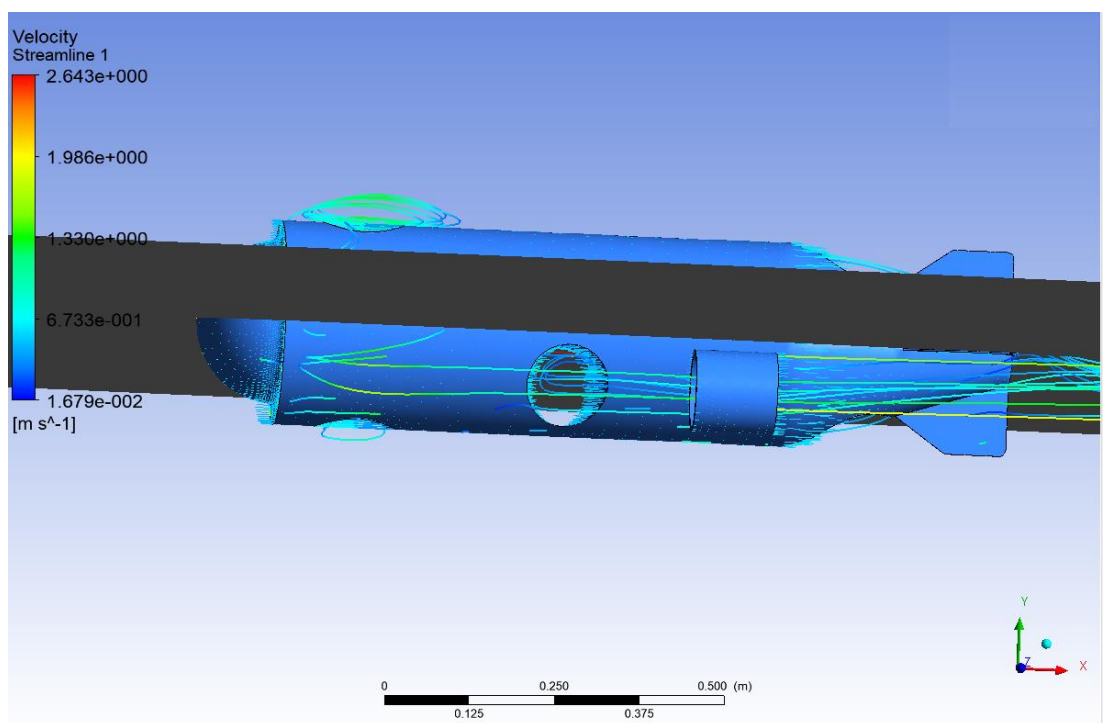

Fig. 9. Velocity over half of body 


\section{CONCLUSION}

The simulated result is going to be verified with the experimental tests in basic and sea water. Future works could improve the accuracy of the CFD results by comparing the numerical simulation to the ROV using real-time adaptive identification approach in sea trial.

\section{REFERENCES}

[1] Committee on Autonomous Vehicles in Support of Naval Operations Naval Studies Board Division on Engineering and Physical Sciences, Autonomous Vehicles in Support of Naval Operations, The National Academies Press, Washington, D.C., www.nap.edu, 2005.

[2] Christ R. D., Wernli R. L., Sr., The ROV Manual, A User Guide for Remotely Operated Vehicles, Second Edition, Butterworth-Heinemann, 2014.

[3] Rusu E., Mecanica, Editura Universității Dunărea de Jos, 2001.

[4] Rusu E, Numerical Simulations of the Current Field In The Black Sea Basin, Constanta Maritime University Annals 19, https://trid.trb.org/view/1309931, 2013.

[5] Ansys CFX software, https://caeai.com/ansys-softwaresupport/ansys-software/computational-fluid-dynamicsansys-cfx-and-fluent-cfd-software 